\title{
Design and Development of AlgoWBIs
}

\author{
Kavita \\ Research Scholar \\ Banasthali University \\ Rajasthan, India
}

\author{
Dr. Abdul Wahid \\ Head of Department of CS \& IT \\ MANUU, Central University \\ Hyderabad, India
}

\author{
Dr. G N Purohit \\ Dean, Department of Apaji Institute of \\ Mathematics \& Applied Computer \\ Technology, Banasthali University \\ Rajasthan, India
}

\begin{abstract}
AlgoWBIs has been developed to support algorithm learning. The goal to develop this tool is to empower educators and learners with an interactive learning tool to improving algorithm's skills.

The paper focuses on how to trim down the challenges ofalgorithm learning andalso discusses how this tool will improve the effectiveness of computer facilitated interactive learning and will support in reducing stress of learning. It will aid computer science graduate and undergraduate learners.Perspective development model has been used for development to enhance the tool's features.
\end{abstract}

Keywords-Algorithm, Instructional design; Web-Based Instruction system (WBIs); Meta learning; Self-paced learning; Web-Based learning; Interactive learning; computer based learning; personalized learning

\section{INTRODUCTION}

Interactive learning system, in contrast to the traditional learning system is more powerful and in favors of entire education system. Interactive learning tools support and allow learners and educators to actively participate in the learning process.

Various interactive learning tools have been developed and are being developed to empower educators in support to change the way teaching and learning occurs[1].Algorithm learning is critical concern for most of the computer science learner and educators. The tool AlgoWBIs is developed to support the instructors and the learners of the information technology and computer science graduate and undergraduate courses. The tool allows students to explore the algorithms for various sorting techniques. The tool not just support learning rather presents simulation, and self assessment approach to test knowledge level[2].

In this paper literature review discusses about the research done this area and summarize with various interactive tools. These tools are available for Electrical Engineering and Electronics, interactive learning modules for PID control, design and development of a web-based interactive software tool for teaching operating systems, DsCats: Animating Data

Structures and PyAlgo as a learning platform for algorithm and data structure.

Further the paper talks about the motivation for this research and descried how and why it is constructive for learners and educators. Model formulation in the subsequent section is discussed. A model which is followed to develop the tool is depicted and described in detail. This section is all about the development process of the tool.

Overall development and the content present in the tool discussed in the consecutive section. This section describes the development of the tool. How the learner can navigate from one topic and page to another one. Finally the paper discusses the limitations and future scope of the tool.

\section{LITERATURE REVIEW}

Justin Cappos \& Patrick Homer (2002) Justin Cappos and Patrick Homer has developed Data Structure Computer Animation Tools called DsCats is available for classroom use. This tool supports educator presentations, student experimentation, and programming assignments. It is an animated tool designed for educational use. The tool implements binary search tree, AVL tree, and B-Tree data structures. DsCats implements a number of new features to facilitate its use as a learning tool. The features presented in the tool are features not commonly present in other tools. These include the ability vary the level of detail during the animation, move backward and forward at will through an animation, and the tool display large data sets too.

U. Antonovičs \& E E. Priednieks (2006) reviewed the literature and presented an Interactive Learning Tools for Electrical Engineering and Electronics. They have implemented original student centered interactive learning tools for higher and vocational schools in Latvia. The tool presents laboratory practice simulations, circuit calculation programs, and learning exercises. Here the interactive learning tool is basically designed to support distance learning courses.

The computer-based learning tool has various advantages for the learners. These are interactive learning in the "computer-student" mode, study material is user-friendly, and learners have the opportunity to choose an individual time of learning. Another advantage of the tool is the evaluating and self assessment could be done by the learners and further the education cost is also reduced. Lejla Abazi-Bexheti et al. (2007) reviewed and concluded with an Interactive Multimedia Learning Systems (IMLS). The main objective of the researchers is to create an additional learning tool that combines on-screen text, graphics, animations, audio and video. The researcher concluded with the tool in order to 
improve the learning process.

Jose Luis Guzman et al. (2008) describes a collection of interactive learning modules for PID control. It is based on the graphical spread sheet metaphor. The modules are designed to speed-up learning and to enhance understanding of the behavior of loops with PID controllers. The modules are implemented in Sysquake, a Matlab dialect with the strong support of interaction. Radio Dragusin and Paula Petcu (2010) designed and develop a tool named PyAlgo for the students following the bachelor level course on Algorithm and Data Structure. The tool focuses on functionality including a library of algorithms and a benchmarking tool.

Aristogiannis Garmpis (2011) after reviewing the literature, researcher developed Design and Development of a Web-based Interactive Software Tool for Teaching Operating Systems. The tool is a complement the existing teaching and learning methods of Operating Systems. The aim of the researcher is not to obsolete the existing pedagogical approach but rather will support the instructor and students for a better understanding of the memory management operations and especially the page replacement algorithm's operation to be used in everyday OS classrooms. The software is intended to support undergraduate students so that they can easily explore the operations of the algorithms through an interaction with the tool. According to the researcher students can explore each algorithm's mechanism separately using this tool. The students will be able to learn from their mistakes as shown automatically by the software. Sebastian Dormido et al. (2012) Researchers reviewed literature and presented an interactive software tool for the loop shaping design of fractional-order PID controllers. The presented tool allows determining automatically the controller parameters by mapping a point of the process Nyquist plot to a point of the loop transfer function Nyquist plot. According to the researchers this kind of Computer Aided Control System Design tools are very useful from an educational viewpoint and in allowing a widespread use of fractional PID controllers in the industry.

\section{Motivation}

Bearing lot many advantages over traditional learning interactive learning becoming popular among universities, school and colleges, instructors and the students. The learning process that encourages the learners to think, write and to talk about is known to be an interactive learning. Interactive learning helps the learner to be more dynamic and active.

Keeping interactive learning's increased requirement in mind literature review is done for interactive algorithm learning tools. Literature supports available tools are learning algorithm. Some are providing learning along with self assessment, some are covering learning and simulation, and few are having only a simulation.Malmi [3] proposed a framework TRAKLA2, for building interactive algorithm simulation exercises only. PyAlgo supports learning platform for algorithm and data structure. The main features of PyAlgo are developing, organizing, and benchmarking algorithms.
An interactive tool named AlgoWBIs for algorithm learning is presented, covering learning, example, simulation, and self assessment all together. Graphical representation of existing tools along with the disclosure of our tool is presented in figure-1. The tool presented here encourages the learners of algorithms to be more active and attentive during learning.

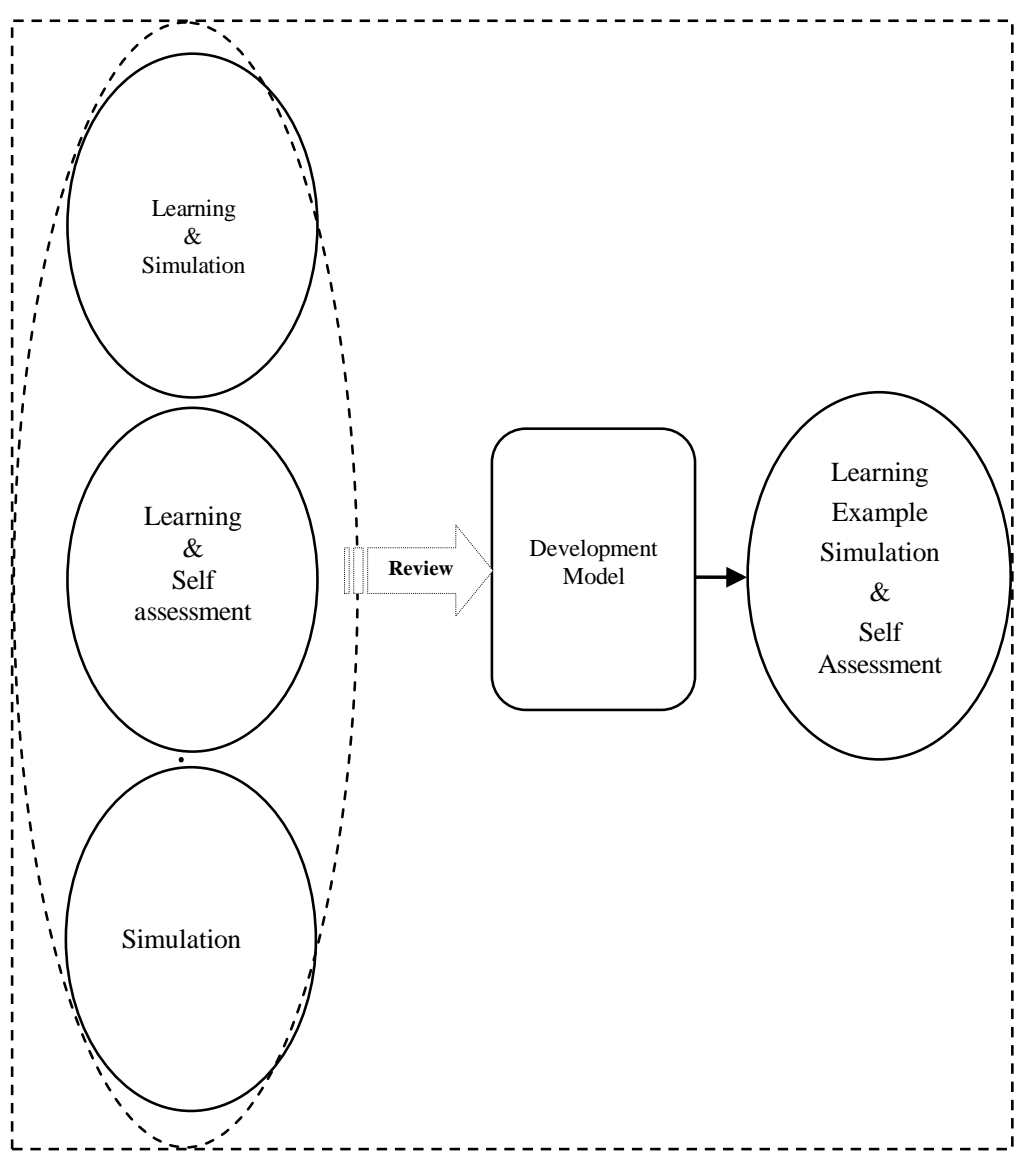

Fig. 1. Review and Development Model

In this figure left side oval shows the available tool for algorithm learning. As shown some of the available tools support learning along with the simulation, learning and self assessment and few supports only simulations. The arrow and rectangle shows that the review is done of the available tools and then follows the development model.

The development model is described in detail in the consecutive section. Finally a new tool for algorithm learning is presented in the right side oval. The new tool is also described in the AlgoWBIs development and content sections.

\section{MODEL FORMULATION}

One major approach to improve the interactivity of the software is the use of appropriate model. These models are helpful in providing feedback and also supportive in improving and innovative insights for designing and developing excellent interactive system [4]. A model provides information about any activity. That activity Anita Lee-Post elearning success perspective model, that address the questions 
of how to design, development, and delivery of successful elearning systems [5] may include designing, development, installation or testing of any system [6].

After judging, suitability of Anita Lee-Post's perspective model and incremental model and following the model is used (figure-2) is followed to develop this tool.

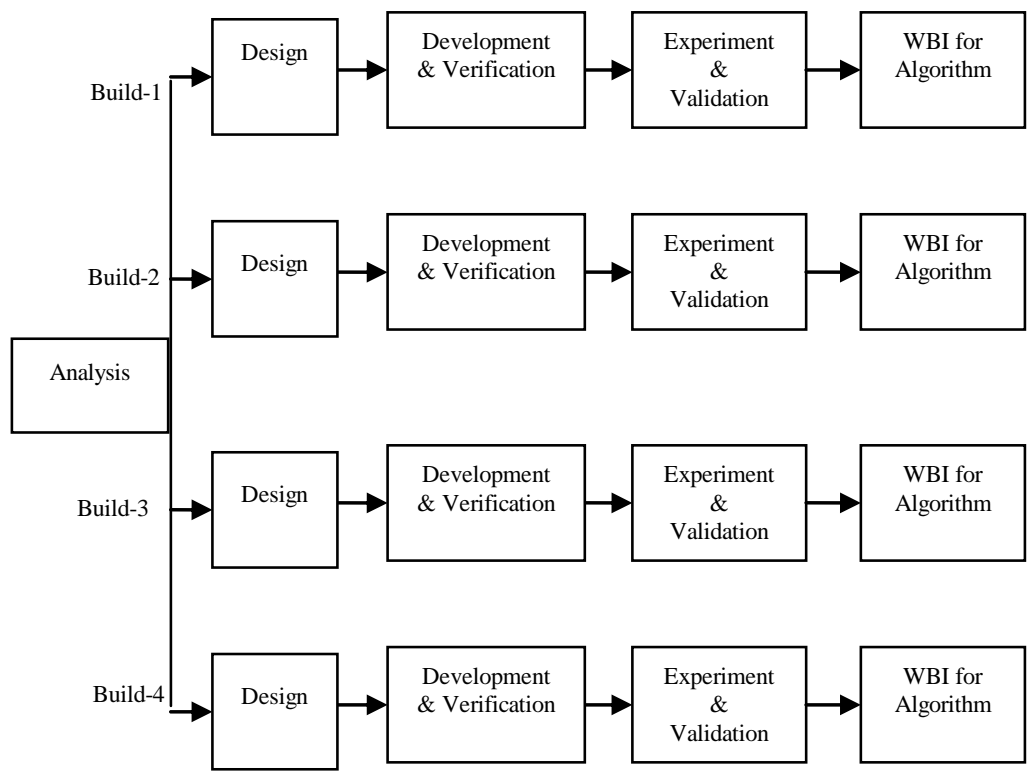

Fig. 2. Perspective Incremental Life cycle model for WBI for Algorithm

Development model used here is based on perspective model, which often can be used as a specification of something to be created. In this model analysis phase allowed us to define the goals and functions to the tool in favor of learners and instructors. Each built sums up with the running software covering the designing, development and verification and experiment and validation. The real code is written in development phase. White box testing is also done in this phase to verify code. Experiment and validation are covering black box testing for each build.

\section{Algowbis Development And Content And FeAtures}

The major challenge in facilitating educators is providing them a meaningful and interactive learning tool [7]. Development of interactive tool requires diversified knowledge including knowledge of interactive tools along with the programming skills, and command on the subject for which tool is being developed. Knowing the learner's psychology is extremely helpful for the success of such tools [8].

Tools interactivity helps in engaging learners during learning that is why the focus should be on how to increase the interactivity? The main features of interactive tool include interactivity, self assessment, navigation between topics, relevance and coverage of content.

Content is required to be relevant to fulfill the need of the course. The tool AlgoWBIs covers all the relevant content for algorithm learning. It is also considered the depth of the topic is sufficient. "Learning might suffer if the sequence is chosen improperly" [9], For the purpose of improvement in learning it is required to develop a learning tool having the proper sequence of topic coverage, which has been taken care of.

Another focus is given on content's navigation. Learners should be equipped with the freedom to navigate to the topics to some extend [9]. To assess learner's knowledge appropriate quizzes is required with online evaluation. In order to enhance learning Evaluation is done by the tool immediately after learner go through the self assessment. This evaluation supports learners to judge their knowledge level after learning any topic.

Extendibility of the tool is also possible when required. This feature will reduce the cost of learning and development of new algorithm learning tools. The tool addresses the personalized needs of the learners which would nurture their knowledge and skills. Further the system would bridge the gap between the learners and the instructors during learning algorithms and would promote the platform for sharing their ideas and knowledge.

This paper has comprehensive descriptions related to the development of the presented tool. The tool presents the learner with a sequence of choices, each containing subchoices or sub-menu. The learner can respond by choosing one of the choices given and system performs a corresponding action. Learning options provided with the tool are:

1) Selection sort

2) Bubble sort

3) Insertion sort

4) Quick sort

The development of the tool starts with the splash screen. After the splash screen learner's interface presents four learning options as mentioned above. Depending on the current knowledge level individual learner may start learning. Unlike classroom learning each learner independently can start learning rather than forcing them to go with the topic being taught in the classroom.

The tool is developed in such a manner that the learners first will go through the learning of the topic he/she wants to learn. The detailed content is presented to the learners. This includes the basic concept of the topics for the example if learner goes through the learning of the quick sort will first get to know about what a quick sort is?

After learning about a topic, an example is presented for better understanding, during example's presentation if learner wants to go through the topic again s/he can navigate to that. An exercise will be given after going through the example. If the learner is competent enough to complete the given exercise must go through the topic again.

Finally the self assessment quiz is presented which helps the learner to assess their knowledge level. Once the learner clears the one level can move to the further topic. It is clearly 
defined what action is required to take further. A learner could navigate through a topic is being learned and could navigate to the main menu.

Other than four learning options, menu also has an exit option to quit from the main menu. Each sorting has four sections:

1) About sorting -This section covers all the aspects of particular sorting. It includes an introduction, algorithm for sorting, sorting function written in $\mathrm{C}$ programming language and complexity of sorting. The learner can navigate backward and forward within the given options using navigation buttons. If the learner wants s/he can exit from the topic any time and come to the main menu.

2) Example -Purpose of this section is to investigate the properties of various algorithms and to enhance the knowledge of learner by showing simulation. It allows the students to understand how sorting algorithm works.

3) Exercise - This section is consisting of a problem provided to learners. To do the exercise learners are required to use knowledge extracted from the prior sections. It is a highly interactive section, allowing learners to make use of knowledge to explore and judge their understanding of the topic. Here learners are asked to move array values to the correct positions interactively. Exercise is the most important option for the learners associated with each sorting.

4) Quiz - To allow learners to measure their knowledge, tool provides quizzes. This self assessment section allows learners to test knowledge they gather from the previous sections. Each quiz has fifteen questions with the four optional answers. The learner will be asked to select a single answer for each question. Answers of the questions will be evaluated automatically by system and finally result will be displayed to the learner. The result of the quiz will be helpful to let the learner know about the knowledge level [10]. Other than the above mentioned options, an exit option in each topic allows learners to quit from the topic being learned. There is a menu button to allow learners to go on the main menu of the tool. Going through all above mentioned options is very simple as tool is very interactive and user friendly.

The overall functionality of tool is depicted in figure-3. Initially when learner interacts with the system will go through the login verification. After successful verification learning options will appear, which includes insertion sort, quick sort, bubble and selection sort. The figure also has a proposed algorithm to be implemented in future.

All these sorting algorithms have multilayer process in which first layer covers the details about sorting, second layer covers the example for each algorithm whereas third layer, simulation is the most interactive in nature and asks the learners to move array values to the desired positions according to the sorting technique and fourth and last layer allow learners to check their progress in terms of quizzes for each algorithm learned before.

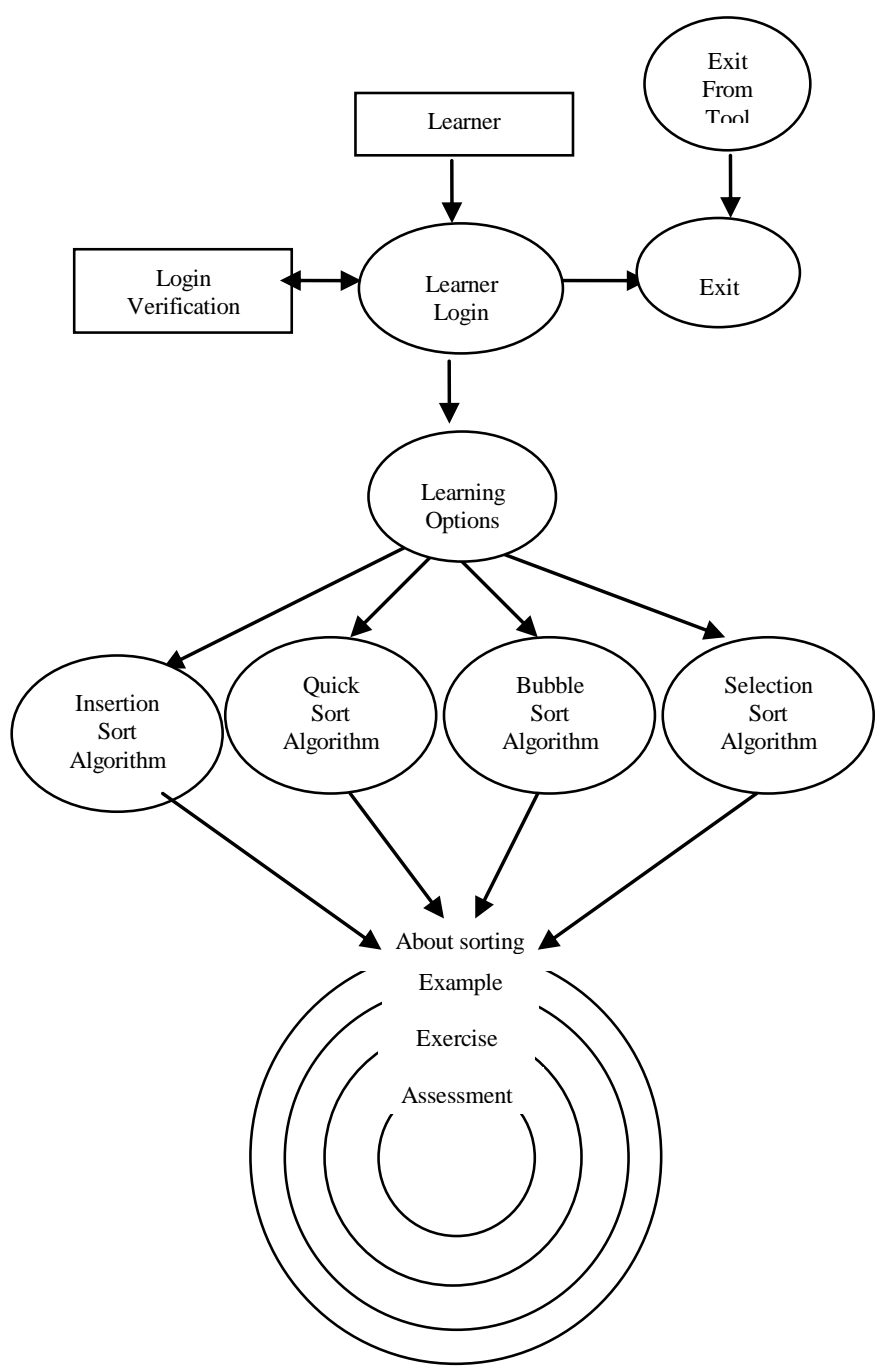

Fig. 3. Functionality of tool AlgoWBIs

\section{LimitATIONS}

The AlgoWBIs is developed to support interactive learning with keeping the thing in mind that there may not be full utilization of the tool by the learners and the instructors without proper training, however messages are being prompted whenever required.

Another limitation includes the number of algorithm implementation in the system. Initially the system facilitates the learning for four sorting. Sorting included in are insertion sort, quick sort, bubble and selection sort. 


\section{CONCLUSION AND FUTURE WORK}

The study is summarized with a highly interactive tool to overcome the stress of learning and make the learning easy and interactive. The emphasis in this study has been put on the learning of sorting. Modularity and expandability is also kept in mind during development. The tool is developed with Macromedia Authorware, which is deliverable through Network, CD and DVD, Internet etc.

Although this tool fulfills most of the learning requirements, there is always room for improvement. The tool could be expanded in future to cover more algorithms. Further version will cover learning of searching algorithms.

\section{REFERENCES}

[1] Sessoms, D. "Interactive instruction: Creating interactive learning environments through tomorrow's teachers" International Journal of Technology in Teaching and Learning, Vol, 4(2), pp. 86-96, 2008

[2] Garmpis, A. "Design and Development of a Web-based Interactive Software Tool for Teaching Operating Systems" Journal of Information Technology Education, Vol. 10, 2011.

[3] Malmi, L., Karavirta, V., Korhonen, A., Nikander, J., Seppälä, O., and Silvasti, P. "Visual Algorithm Simulation Exercise System with Automatic Assessment: TRAKLA2." Informatics in Education, Vol. 3(2), pp. 267 288,2004 .

[4] Arthur, J. D. "A Descriptive/Prescriptive Model for Menu-Based Interaction.” International Journal of Man-Machine Studies, Vol.25(1), pp. 19-32, 1986

[5] Lee-Post, A.(2009). “e-Learning Success Model: an Information Systems Perspective.” Electronic Journal of e-Learning. [Online]. 7(1), pp. $61-70$. Available: www.ejel.org

[6] Ludewig, J. (2003). "Models in software engineering - an introduction, Softw Syst Model" Vol. 2, pp. 5-14 / Digital Object Identifier (DOI) $10.1007 / \mathrm{s} 10270-003-0020-3$

[7] Thomas, R. "Interactivity \& Simulationsin e-Learning." Avaiable: http://www.multiverse.co.uk/whitepaper.pdf

[8] Kennedy, D.M. "SOFTWARE DEVELOPMENT TEAMS IN HIGHER EDUCATION: AN EDUCATOR'S VIEW.”, Software Development Teams in Higher Education: An Educator's View, 1998.

[9] Abazi-Bexheti, L., Dika, Z. and Luma, A. "Interactive Multimedia
Learning Systems: An Experience in Developing IMLS for the IT-Skills Course.' http://rootsitservices.com/CustomPages/sdlifecycle.aspx

Available:

[10] Millard,D., Jennings, W., Sanderson A., Wong,A. Patel, A. Brubaker, W., Perala, M. \& Slattery, D. "Interactive Learning Modules for Electrical, Computer and Systems Engineering”, 1997.

[11] Nikolaou, A., Koutsouba, M. (2012). "Incorporating 4MAT Model in Distance Instructional Material- An Innovative Design." European Journal of Open, Distance and E-Learning, Available: http://www.eurodl.org/?article=497

[12] Bellotti, F., Berta, R., De Gloria, A., \& Primavera, L. "Supporting authors in the development of task-based learning in serious virtual worlds." British Journal of Educational Technology, Vol. 41(1), pp. 86-107, 2010.

[13] Hadjerrouit, S. “A Conceptual Framework for Using and Evaluating WebBased Learning Resources in School Education." Journal of Information Technology Education, Vol. 9, pp. 53-79, 2010.

[14] Kelly, P., \& Stevens, C. (2009). "Narrowing the distance: using e-learner support to enhance the student experience." European Journal of Open, Distance and E-Learning, Vol. 2. Available: http://www.eurodl.org/materials/contrib/2009/Kelly_Stevens.pdf

[15] Hansen, S.R. \& Narayanan, N. H. "On the role of animated analogies in algorithm visualizations." In: Proceedings of the Fourth International Conference of The Learning Sciences, Lawrence Erlbaum Associates, Mahwah, NJ, pp. 205-211, 2010.

[16] Seay, F. \& Catrambone, R. "Using animations to help students learn computer algorithms: A task analysis approach." Artificial Intelligence in Education, pp. 43-54, 2001.

[17] Craig Larman, Victor R. Basili ( 2003). "Iterative and Incremental Development: A Brief History". IEEE Computer (IEEE Computer Society), Vol. 36 (6) pp. 47-56. doi:10.1109/MC.2003.1204375. [01-10-2009].

[18] Lee-Post, A. "e-Learning Success Model: an Information Systems Perspective." Electronic Journal of e-Learning, Vol. 7(1), pp. 61 - 70, Available: www.ejel.org, 2009

[19] Antonovičs, U., Priednieks, Ē. "Interactive Learning Tools for Electrical Engineering and Electronics Course." Electronics And Electrical Engineering, 2006

[20] Jose' Luis Guzmán , Karl J. A stro“m , Sebastia’n Dormido ,Tore H“agglund, Yves Piguet. "Interactive learning modules for PID control."

[21] ]Dormido, S., Pisoni, E. \& Visioli, A. "Interactive tools for designing fractional-order PID controllers." International Journal of Innovative Computing, Information and Control, Vol. 8(7), 2012. 